\title{
Single dilution ELISAs using soluble piroplasm, cellular schizont and soluble schizont antigens for the detection of antibodies against Theileria annulata
}

\author{
Anju MANUJA ${ }^{\mathrm{a}}$, Anil K. NiCHANI ${ }^{\mathrm{b} *}$, Rakesh KUMAR ${ }^{\mathrm{c}}$, \\ Rameshwer D. SHARMA ${ }^{\text {, }}$ Balwinder KUMAR ${ }^{\mathrm{a}}$ \\ ${ }^{a}$ Central Institute for Research on Buffaloes, Hisar (Haryana) 125 001, India \\ ${ }^{\mathrm{b}}$ AICRP on Blood Protista, College of Veterinary Sciences, CCS Haryana Agricultural \\ University, Hisar (Haryana) 125 004, India \\ ${ }^{\mathrm{c}}$ Department of Veterinary Clinical Medicine, CCS Haryana Agricultural University, \\ Hisar (Haryana) 125 004, India \\ ${ }^{\mathrm{d}}$ Department of Veterinary Epidemiology and Preventive Medicine, CCS Haryana Agricultural \\ University, Hisar (Haryana) 125 004, India
}

(Received 4 September 2000; accepted 19 December 2000)

\begin{abstract}
Single dilution ELISAs were standardised for the determination of antibody titres against Theileria annulata using three antigens namely soluble piroplasm, cellular schizont or soluble schizont antigens. Antibody titres of 20 cattle serum samples of known identity were determined by multi-dilution ELISA using the three antigens. The ratio of the optical density (OD) of known positive and known negative sera at different serum dilutions were calculated and termed as positive/negative $(\mathrm{P} / \mathrm{N})$ ratios. Coefficients of correlation (r) were calculated between the $\mathrm{P} / \mathrm{N}$ ratios at different dilutions of known sera and their $\log _{10}$ antibody titres by multi-dilution ELISA. The value of " $r$ " was the highest at the dilution of 1:400. From the $\log _{10}$ antibody titres of known sera and their P/N ratios at the dilution of $1: 400$, regression equations $\left(Y=a+b X\right.$, where $Y=$ predicted $\log _{10}$ titre, $X=$ the $P / N$ ratio at 1:400 dilution) were calculated separately for the three antigens. Thus, the equations $Y=1.63$ $+1.35 \mathrm{X}$ for soluble piroplasm, $\mathrm{Y}=2.67+0.547 \mathrm{X}$ for cellular schizont and $\mathrm{Y}=1.817+0.663 \mathrm{X}$ for soluble schizont antigens were derived. Test sera were diluted to 1:400 and their OD were read in duplicate wells and converted to $\mathrm{P} / \mathrm{N}$ ratios. The antibody titres were predicted from the $\mathrm{P} / \mathrm{N}$ ratios using the above mentioned regression equations. Twenty randomly selected sera tested by single and multidilution ELISAs showed non-significant differences $(P<0.01)$ between antibody titres. Antibody titres of 90 unknown field sera of cattle were determined by single dilution ELISA. The piroplasm antigen detected higher antibody titres followed by cellular schizont and soluble schizont antigens. The study revealed that a single dilution ELISA could be successfully used for field epidemiological studies of tropical theileriosis.
\end{abstract}

Theileria annulata / single dilution ELISA / piroplasm / schizont / regression

* Correspondence and reprints

Tel./fax: (91) 1662 37038; e-mail: anichani@nde.vsnl.net.in 
Résumé - ELISA à dilution unique utilisant l'antigène de piroplasme soluble, de schizonte cellulaire ou de schizonte soluble pour la détection d'anticorps contre Theileria annulata. Un ELISA à dilution unique a été standardisé pour la détermination des titres en anticorps contre Theileria annulata, en utilisant trois antigènes : l'antigène de piroplasme soluble, de schizonte cellulaire, ou de schizonte soluble. Les titres en anticorps de 20 échantillons de sérums d'identité connue ont été déterminés par un ELISA à dilutions multiples, avec les trois antigènes. Le rapport de la densité optique (DO) de sérums positifs connus sur la DO de sérums négatifs connus, à différentes dilutions, a été calculé et a été appelé le rapport positif/négatif (P/N). Le coefficient de corrélation (r) entre les rapports $\mathrm{P} / \mathrm{N}$ de sérums connus et leur titre en anticorps $\left(\log _{10}\right)$ déterminé par ELISA à dilutions multiples, a été calculé pour différentes dilutions des sérums. La plus forte valeur de « $\mathrm{r}$ » correspondait à une dilution de $1 / 400$. À partir des titres $\left(\log _{10}\right)$ en anticorps de sérums connus et leur rapport $\mathrm{P} / \mathrm{N}$ à une dilution $1 / 400$, des équations de régression ont été calculées séparément pour chaque antigène $\left(\mathrm{Y}=\mathrm{a}+\mathrm{bX}\right.$, où $\mathrm{Y}=$ titre prédit en $\log _{10} ; \mathrm{X}=\operatorname{rapport} \mathrm{P} / \mathrm{N}$ à la dilution $\left.1 / 400\right)$. Les équations suivantes ont ainsi été dérivées : $\mathrm{Y}=1,63+1,35 \mathrm{X}$ pour le piroplasme soluble ; $\mathrm{Y}=2,67$ $+0,547 \mathrm{X}$ pour le schizonte cellulaire, et $\mathrm{Y}=1,817+0,663 \mathrm{X}$ pour le schizonte soluble. Les sérums testés ont été dilués à 1/400 et leurs DO ont été lues chacune dans deux puits puis converties en rapport $\mathrm{P} / \mathrm{N}$. Les titres en anticorps ont été prédits à partir des rapports $\mathrm{P} / \mathrm{N}$, en utilisant les équations de régression correspondantes. Vingt sérums sélectionnés au hasard ont été testés à la fois par ELISA à dilutions multiples et par ELISA à dilution unique ; il n'y a pas eu de différence significative entre les titres en anticorps obtenus par les deux méthodes $(P<0,01)$. Les titres en anticorps de 90 sérums prélevés sur le terrain ont été déterminés par ELISA à dilution unique. Dans ces échantillons, l'antigène de piroplasme détectait les anticorps aux titres les plus élevés, suivi du schizonte cellulaire, puis du schizonte soluble. L'étude a révélé que l'ELISA à dilution unique peut être utilisée avec succès dans des études épidémiologiques de terrain sur la theilériose tropicale.

Theileria annulata / ELISA à dilution unique / piroplasme / schizonte / régression

\section{INTRODUCTION}

Theileria annulata is an important haemoprotozoa that causes a serious leucoproliferative disease of cattle bovine tropical theileriosis in tropical and subtropical countries. The disease is of particular economic importance since exotic "European" cattle were imported into the tropics to increase the productivity of local "Zebu" cattle as exotic cattle and their cross-breds are highly susceptible [1]. The diagnosis of the disease has traditionally been confirmed by examination of Giemsa stained thin blood smears and/or lymph node biopsy smears. Following infection, the surviving cattle carry low numbers of piroplasms in erythrocytes for long periods. Examination of smears of animals living under field conditions has been extensively used to estimate the prevalence of carriers and exposure to $T$. annulata infection $[1,4]$. However, such a technique is time consuming and may not be very sensitive since piroplasms cannot be detected in blood smears of all carrier animals. Therefore, sensitive and specific serological tests are required for large-scale sero-epidemiological studies and also for monitoring immune responses of vaccinated animals in the field. Enzyme Linked Immunosorbent Assay (ELISA), being a highly sensitive, specific and objective assay, is recommended for the detection of antibodies against $T$. annulata for seroepidemiological studies $[5,9,11]$. In conventional ELISA, costly bioreagents are required in large quantities for the estimation of antibody titres, since many dilutions of each serum need to be tested. Multidilution ELISAs are cumbersome, time consuming and expensive when large numbers of field samples have to be evaluated. Multidilution ELISAs have been successfully converted into single dilution ELISAs for detecting antibodies against various pathogens involving large numbers of samples $[6,10,13]$. We, therefore, developed single dilution ELISAs for detection of 
antibodies against $T$. annulata for our epidemiological studies using three antigenic preparations namely cellular schizont, soluble schizont and soluble piroplasm antigens.

\section{MATERIALS AND METHODS}

\subsection{Antigens and procedure}

Three antigens namely soluble piroplasm, cellular schizont and soluble schizont antigens were used. Soluble piroplasm and soluble schizont antigens were prepared as described previously [9]. The soluble piroplasm antigen was prepared from high parasitaemic erythrocytes collected from a calf suffering from acute theileriosis. The soluble schizont antigen was prepared from an in vitro propagated T. annulata (Hisar) schizont cell culture line. The protein contents of the soluble piroplasm and soluble schizont antigens were 3.75 and $2.1 \mathrm{mg} \cdot \mathrm{mL}^{-1}$, respectively as estimated by the Lowry's method [7]. The cellular schizont antigen was prepared from a T. annulata (Hisar) schizont cell line as described by Manuja et al. [8]. The test procedure for conducting a multi-dilution ELISA, as described previously [9], was followed.

\subsection{Serum samples}

Serum samples collected from newborn calves were used as known negative sera. Previously tested serum samples, collected from animals one month after vaccination with a $T$. annulata cell culture vaccine, were used as known positive sera [9]. Unknown field serum samples from 90 cattle were used as test sera.

\subsection{Development of a single dilution ELISA}

For standardisation of a single dilution ELISA, the basic principle described by
Westbury et al. [13] for detecting antibodies against the FMD virus was followed. Antibody titres of 20 serum samples of known identity were determined by multi-dilution ELISA using the three antigens as described previously [9]. The optical densities (OD) of all test sera and known negative sera were recorded at two fold serum dilutions from $1: 50$ to $1: 800$. The ratios of OD of test sera and known negative sera at different serum dilutions were calculated and termed as positive/negative $(\mathrm{P} / \mathrm{N})$ ratios. The coefficient of correlation (r) was calculated between the $\mathrm{P} / \mathrm{N}$ ratio at different dilutions of the test sera and the $\log _{10}$ transformation of antibody titres was estimated by multi-dilution ELISA. The dilution of the serum showing the highest value of " $r$ " was chosen for standardising the single dilution ELISA. Regression equations that is $\mathrm{Y}=\mathrm{a}+\mathrm{bX}$ were calculated separately for each of the three antigens (where $\mathrm{Y}=$ Predicted log titre by single dilution ELISA, $\mathrm{a}=$ Constant, $\mathrm{b}=$ Regression coefficient and $\mathrm{X}=\mathrm{P} / \mathrm{N}$ ratio at the selected serum dilution) from the $\log _{10}$ antibody titres of test sera and $\mathrm{P} / \mathrm{N}$ ratio at the serum dilution showing maximum coefficient of correlation. The values of " $a$ " and "b" were calculated using the following equations:

$$
\begin{gathered}
\mathrm{a}=\mathrm{y}-\mathrm{bX} \\
\mathrm{b}=\frac{\Sigma(\mathrm{y}-\overline{\mathrm{y}})(\mathrm{x}-\overline{\mathrm{x}})}{\Sigma(\mathrm{x}-\overline{\mathrm{x}})^{2}}
\end{gathered}
$$

( $y=$ observed value of the dependent variable, $x=$ observed value of the independent variable).

The test serum samples were diluted to the selected dilution, their OD was recorded at $492 \mathrm{~nm}$ in duplicate wells coated with three different antigens using an ELISA reader (Organon Teknika, Italy). The mean OD for each sample was converted to the $\mathrm{P} / \mathrm{N}$ ratio and the antibody titres were predicted using the regression equations separately derived for the three antigens. For the validation of the results, the antibody titres 
of twenty cattle sera obtained by single dilution and multi-dilution ELISA using three antigens were compared statistically by applying a paired-t test.

\subsection{Application of the test on field samples}

Antibody titres of 90 unknown field cattle sera against $T$. annulata were estimated by single dilution ELISA using soluble piroplasm, cellular schizont and soluble schizont antigens. The correlation coefficient (r) between antibody titres obtained using these three antigens was calculated [12]

\section{RESULTS}

\subsection{Standardisation of appropriate serum dilution}

The coefficient of correlation between the $\mathrm{P} / \mathrm{N}$ ratio at different serum dilutions and $\log _{10}$ antibody titres by multi-dilution ELISA were maximum at a 1:400 serum dilution for all three antigens (Tab. I). The mean OD of negative sera levelled off at this serum dilution, whereas that of hyperimmune sera was still high. Therefore, a serum dilution of 1:400 was selected as an optimum dilution for use in single dilution ELISA with all three antigens.

\subsection{Derivation of line of regression}

The $\mathrm{P} / \mathrm{N}$ ratio of 20 sera of known identity at 1:400 serum dilution and their corresponding $\log _{10}$ titres by multi-dilution ELISA showed a good correlation (Fig. 1). The values of " $a$ " (constant) and "b" (regression coefficient) were calculated using these parameters. The regression equations were as follows:

- piroplasm antigen: $\mathrm{Y}=1.630+1.35 \mathrm{X}$;

- cellular schizont antigen: $\mathrm{Y}=2.670+$ $0.547 \mathrm{X}$;

- soluble schizont antigen: $\mathrm{Y}=1.817+$ $0.663 X$.

\subsection{Comparison of multi-dilution and single dilution ELISA}

Serum antibody titres of 20 serum samples of known identity determined by multidilution and single dilution ELISAs using three antigens were similar (Fig. 2). The comparison of antibody titres using the two tests revealed that the calculated " $t$ " values for all three antigens were lower than the tabulated value and thus non-significant (1.73, 1.88 and 0.02 for piroplasm, cellular schizont and soluble schizont antigens, respectively against the tabulated value of 2.86 at $P<0.01)$. This indicated that the antibody titres obtained by multi-dilution ELISA and single dilution ELISA did not differ significantly $(P<0.01)$. Plotting of antibody titres obtained by multi-dilution

Table I. Correlation between positive/negative ratio at different dilutions of known positive sera and $\log _{10}$ antibody titres using different antigenic preparations.

\begin{tabular}{lccc}
\hline & \multicolumn{3}{c}{ Coefficient of correlation (r) } \\
\cline { 2 - 4 } Serum dilution & Piroplasm antigen & Cellular schizont antigen & Soluble schizont antigen \\
\hline $1: 50$ & 0.584 & 0.202 & 0.300 \\
$1: 100$ & 0.694 & 0.806 & 0.473 \\
$1: 200$ & 0.590 & 0.772 & 0.766 \\
$1: 400$ & 0.910 & 0.813 & 0.880 \\
$1: 800$ & 0.570 & 0.800 & 0.774
\end{tabular}




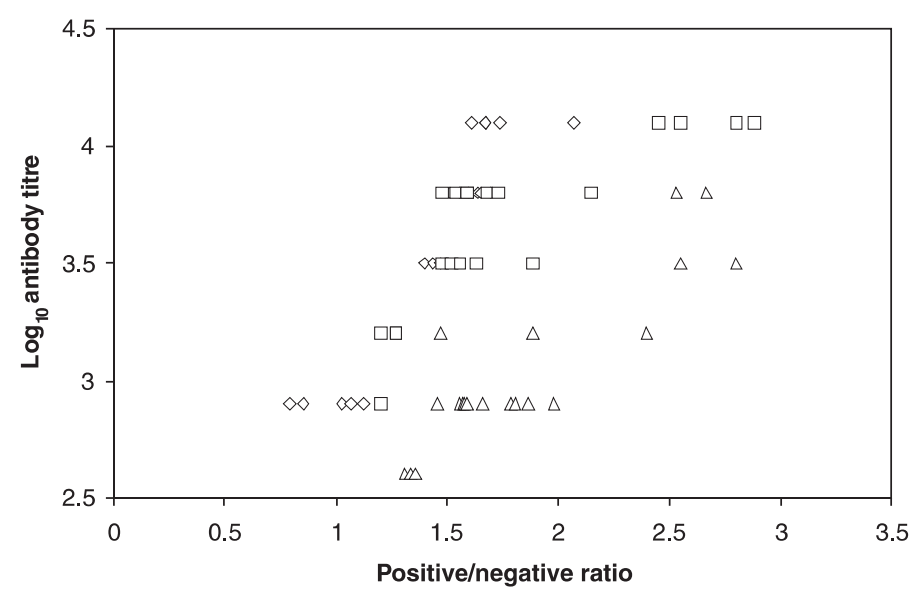

$\diamond$ Piroplasm antigen $\square$ Cellular schizont antigen $\triangle$ Soluble schizont antigen

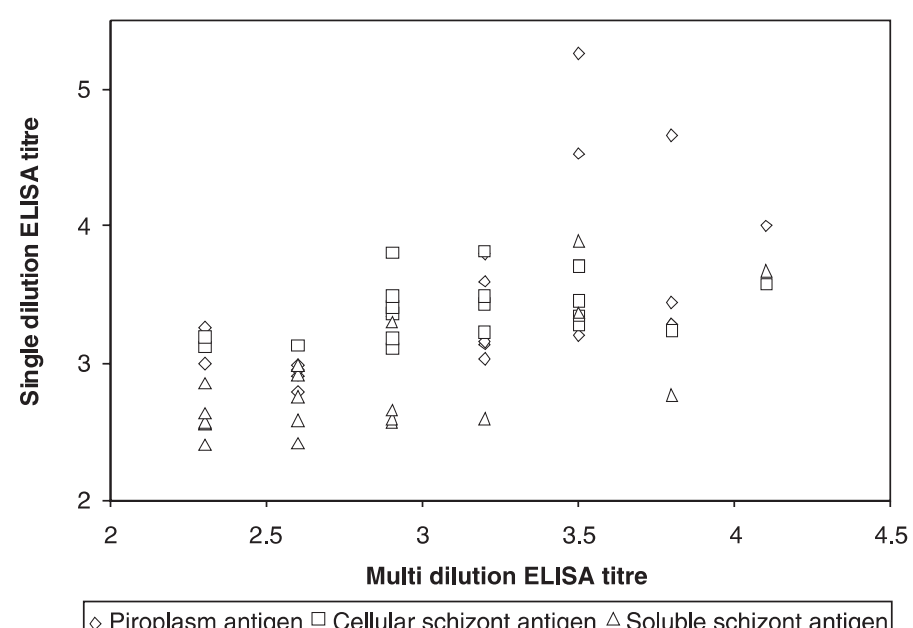

Figure 1. Comparison of multi-dilution ELISA antibody titres with positive/negative ratio at 1:400 serum dilution.
Figure 2. Comparison of antibody titres obtained by single and multidilution ELISA using different antigens.
ELISA with the regression line for single dilution ELISA revealed that the points of antibody titres by multi-dilution ELISA were scattered on or around the line of regression for the three antigens (Fig. 3).

\subsection{Application of single dilution ELISA on field sera}

A majority of the field serum samples exhibited antibody titres ranging from 1:800 to $1: 12800$ by ELISA using piroplasm and cellular schizont antigens. While using the soluble schizont antigen, most of samples $(84.5 \%)$ showed antibody titres up to $1: 800$ (Tab. II). The piroplasm antigen detected higher antibody titres followed by cellular schizont and soluble schizont antigens. A comparison of antibody titres obtained using soluble piroplasm, cellular schizont and soluble schizont antigens showed a good correlation between the three antigens. The coefficient of correlation (r) between 

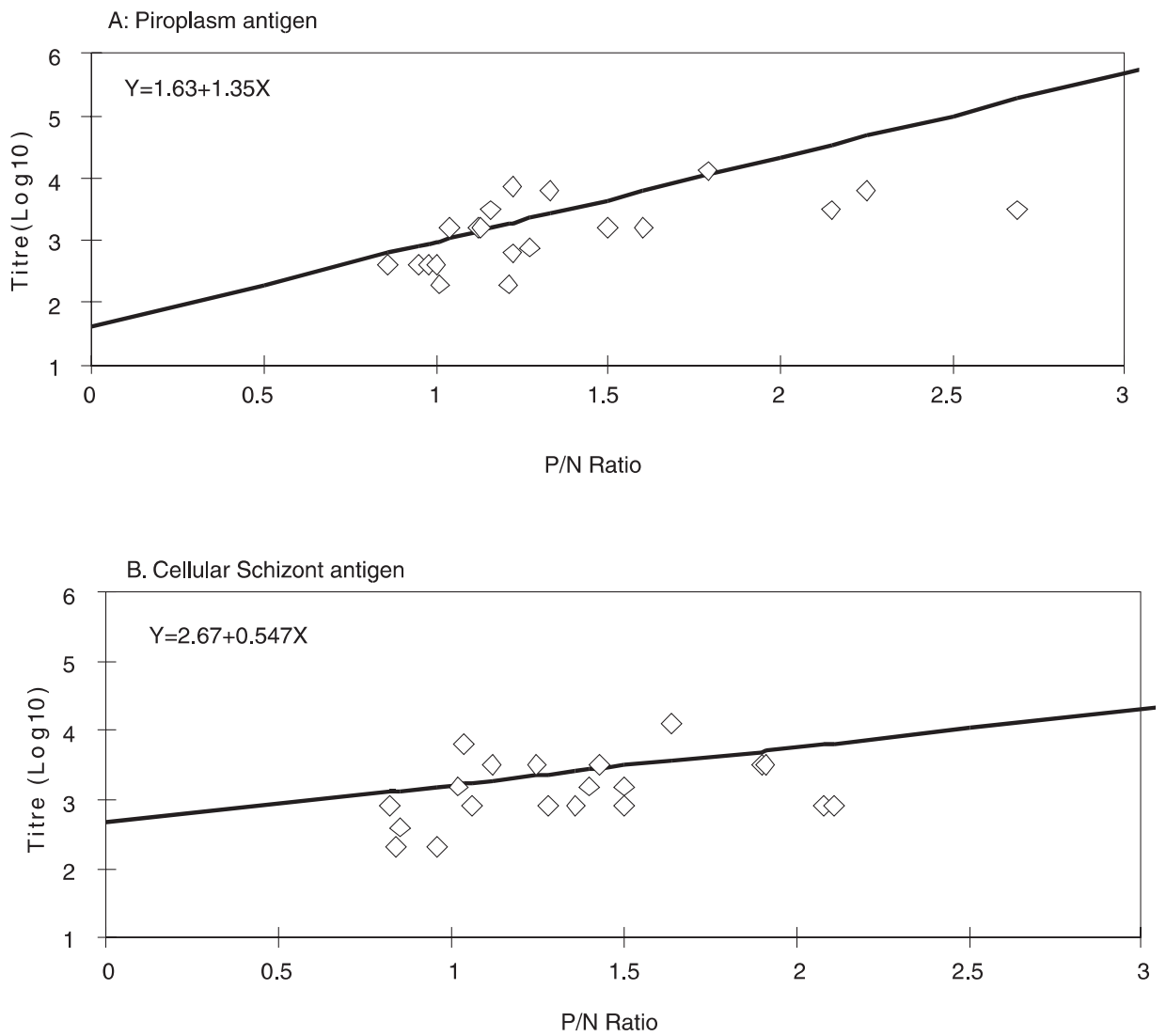

C: Soluble Schizont antigen

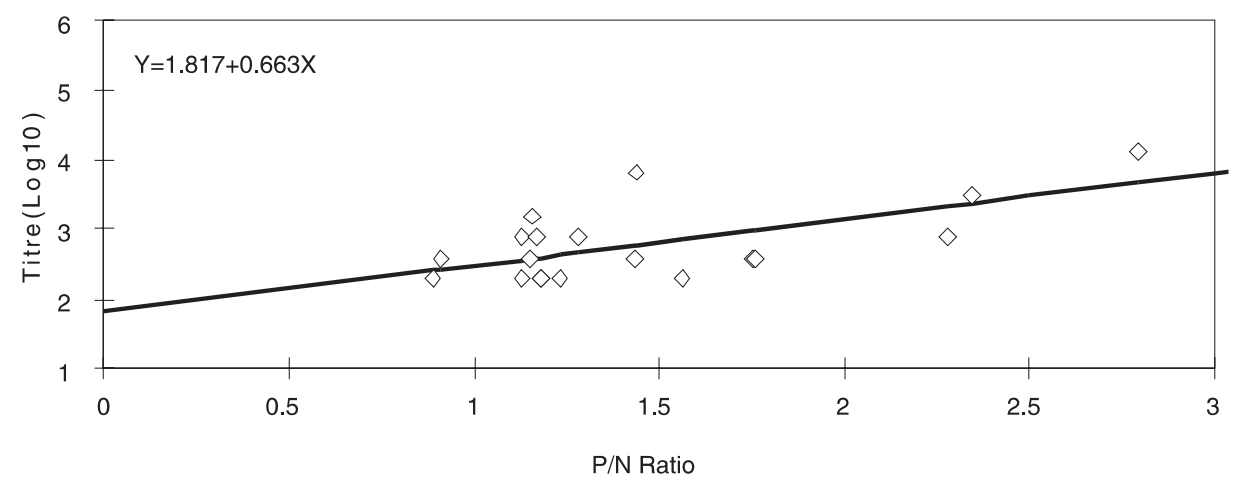

Figure 3. Relationship between antibody titres obtained by multi-dilution ELISA and the line of regression for various antigens. 
Table II. Frequency distribution of antibody titres of 90 field sera obtained by single dilution ELISA using piroplasm, cellular schizont and soluble schizont antigens.

\begin{tabular}{lccc}
\hline ELISA antibody & \multicolumn{3}{c}{ No. of samples $(\%)$} \\
\cline { 2 - 4 } titres & Piroplasm & Cellular schizont & Soluble schizont \\
\hline Up to $1: 400$ & - & - & $44(48.9)$ \\
$1: 400-1: 800$ & $3(3.3)$ & - & $32(35.6)$ \\
$1: 800-1: 1600$ & $25(27.8)$ & $38(42.2)$ & $11(12.2)$ \\
$1: 1600-1: 3200$ & $23(25.6)$ & $47(52.2)$ & $3(3.3)$ \\
$1: 3200-1: 12800$ & $24(26.7)$ & $4(4.4)$ & - \\
$>1: 12800$ & $15(16.7)$ & $1(1.1)$ & - \\
\hline
\end{tabular}

soluble piroplasm and cellular schizont antigen was 0.650 , between soluble piroplasm and soluble schizont antigens was 0.870 and between cellular schizont and soluble schizont antigens was 0.520 . The calculated values of " $r$ " were higher than the tabulated values $(0.33)$ and interpreted as significant $(P<0.01)$, thus showing a positive correlation between the three antigens.

\section{DISCUSSION}

Serological investigations, despite distinct advantages, are yet to be adopted as routine procedures for studying the epidemiology of various diseases especially in developing countries. The main reason for this is the non-availability of suitable serological tests, which could be used economically on a large scale. Single dilution ELISAs have been used effectively for serodiagnosis of various infectious diseases like FMD, pasteurellosis, babesiosis, etc. [2, 10, 13], where large numbers of samples can be tested economically over a short period of time. The OD of hyperimmune sera at different dilutions decreased gradually in multidilution ELISA and the OD at 1:100 dilutions showed high correlation with antibody titres of the samples [8]. On this basis, single dilution ELISAs using soluble piroplasm, cellular schizont or soluble schizont antigens were standardised. A serum sample at the same dilution might not have given the same OD in different tests because of variations in experimental conditions. To overcome this, the ratio of OD of test sera and known negative sera ( $\mathrm{P} / \mathrm{N}$ ratio), instead of OD of the test serum sample was used to standardise the single dilution ELISA. The $\mathrm{P} / \mathrm{N}$ ratios of serum samples were relatively constant in different tests as compared to the OD as reported previously for standardising similar tests for other pathogens $[2,3]$.

The coefficient of correlation between antibody titres and $\mathrm{P} / \mathrm{N}$ ratios obtained for all the three antigens was maximum at a 1:400 serum dilution. Therefore, this serum dilution was chosen to standardise single dilution ELISA. The single dilution ELISA should be standardised in such a manner that it is able to detect optimum antibodies in a wide range of test sera including highly positive as well as negative sera [10]. Therefore, sera of known identity showing a wide range of antibody titres, as reported previously [9], were used to standardise single dilution ELISA and included both known negative and positive sera.

The lines of regression for the three antigens showed that the slope of the curve "b" (regression coefficient) was the highest for the piroplasm antigen followed by soluble schizont and cellular schizont antigens. The highest value for "a" (constant) was observed for the cellular schizont antigen followed by soluble schizont and piroplasm antigens. In order to achieve the best line of regression and to accommodate a wide 
range of samples exhibiting low to high titres, the value of the regression coefficient should be high and the value of the constant should be as low as possible [13]. Keeping this in view, the best line of regression was obtained with the piroplasm antigen followed by the soluble schizont and cellular schizont antigens. The line of regression for the piroplasm antigen intercepted close to zero on the $y$-axis, followed by the soluble schizont and cellular schizont antigens. This value intercept on the $y$-axis corresponds to the possible minimum titre, i.e. cut off titre, which can be estimated by the line of regression. Since the value of the constant was high with the cellular schizont antigen, the cut off titre for this antigen was also high. It does not however, undermine the usefulness of this test for the cellular schizont antigen if some cut off threshold titre is set up using known negative sera.

The comparison of antibody titres obtained by single dilution and multi-dilution ELISA revealed that the results obtained using the two tests were statistically similar $(P<0.01)$ and thus increased the confidence of regression equations. This was also confirmed graphically by close distribution of antibody titres by multi-dilution ELISA to the line of regression. Single dilution ELISA was successfully standardised and also applied on field serum samples, which showed a positive correlation between antibody titres obtained using three antigens. The piroplasm antigen detected higher antibody titres followed by cellular schizont and soluble schizont antigens. This conforms to previously reported results using multidilution ELISA [9]. Exact titre of the sera was determined with the single dilution ELISA, which is not possible in multi-dilution ELISA as it is based on two fold serial dilutions.

The cellular schizont antigen and soluble schizont antigens were prepared from in vitro propagated cultures of $T$. annulata schizonts, whereas the piroplasm antigen was prepared from the blood of a calf showing clinical theileriosis. Though it was easy to prepare the cellular schizont and soluble schizont antigens, yet the results showed that single dilution ELISA using the piroplasm antigen was the best choice for field sero-epidemiological studies.

The study revealed that a single dilution ELISA could be standardised for the detection of antibodies against $T$. annulata using all the three antigens. The best line of regression was obtained with the piroplasm antigen followed by the soluble schizont and cellular schizont antigens. The test was highly economical, time saving and easy to perform on a large number of serum samples as compared to multi-dilution ELISA. This test is, therefore, recommended for use in field epidemiological studies.

\section{ACKNOWLEDGEMENTS}

A.K. Nichani is partly funded by the Wellcome Trust grant No. 044654.

\section{REFERENCES}

[1] Beniwal R.K., Nichani A.K., Sharma R.D., Rakha N.K., Suri D., Sarup S., Responses in animals vaccinated with the Theileria annulata (Hisar) cell culture vaccine, Trop. Anim. Health Prod. 29 (1997) 109S-113S

[2] Beniwal R.P., Nichani A.K., Rakha N.K., Sharma R.D., Sarup S., An immunisation trial with in vitro produced Babesia bigemina exoantigens, Trop. Anim. Health Prod. 29 (1997) 124S-126S.

[3] Briggs D.J., Skeeles J.K., Enzyme Linked Immunosorbent assay for detecting antibodies to Pasteurella Multocida in chickens, Avian Dis. 28 (1983) 208-215.

[4] Flach E.J., Ouhelli H., The epidemiology of tropical theileriosis (Theileria annulata infection in cattle) in an endemic area of Morocco, Vet. Parasitol. 44 (1992) 51-65.

[5] Kachani M., Flach E.J., Williamson S., Ouhelli H., El Hasnaoui M., Spooner R.L., The use of an enzyme-linked immunosorbent assay for tropical theileriosis research in Morocco, Prev. Vet. Med. 26 (1996) 329-339.

[6] Khatri N., Nichani A.K., Sharma R.D., Khatri M., Malhotra D.V., Effect of vaccination on young calves born during winter season in the field with the Theileria annulata (Hisar) cell culture vaccine, Vet. Res. Commun. (in press). 
[7] Lowry O.H., Rosenbrough N.J., Farr A.L., Randall R.J., Protein measurement with Follin's phenol reagent, J. Biol. Chem. 193 (1951) 265-275.

[8] Manuja A., Rakha N.K., Kumar R., Nichani A.K., Sharma R.D., Gupta S.K., Suri D., A fixed cell ELISA for detecting antibodies against Theileria annulata, J. Immunol. Immunopathol. 1 (1999) 41-48.

[9] Manuja A., Nichani A.K., Kumar R., Rakha N.K., Kumar B., Sharma R.D., Comparison of cellular schizont, soluble schizont and soluble piroplasm antigens in ELISA for detecting antibodies against Theileria annulata, Vet. Parasitol. 87 (2000) 93101.

[10] Sorensen K.J., Madekurozwa R.L., Dawe P., Foot and Mouth disease: Detection of antibodies in
Cattle sera by blocking ELISA, Vet. Microbiol. 32 (1992) 253-265.

[11] Suri D., Rakha N.K., Nichani A.K., Sharma R.D., Sarup S., Comparative studies on ELISA and IFAT for assessment of humoral responses in bovine tropical theileriosis, Indian J. Comp. Microbiol. Immunol. Inf. Dis. 17 (1996) 155160.

[12] Wardlaw A.C., Practical statistics for Experimental Biologists, John Willey and sons, New York, 1985.

[13] Westbury H.A., Chamnanpood P., Tangchaitrong S., Doughty, W.J., Single dilution ELISA for detection of serum antibody to foot and mouth disease virus in cattle, Vet. Microbiol. 18 (1988) 273-283. 